\title{
EVALUASI PENGGUNAAN ANTIBIOTIK PROFILAKSIS CEFAZOLIN PADA PASIEN OPERASI DI RUMAH SAKIT PREMIER BINTARO
}

\author{
Humaira Fadhilah, Nurul Chasanah, Ridwan Ruswendi \\ Sekolah Tinggi Ilmu Kesehatan Kharisma Persada \\ Tangerang Selatan, 15417, Indonesia \\ E-mail: humaira@masda.ac.id
}

\begin{abstract}
ABSTRAK
Antibiotik profilaksis adalah antibiotik yang digunakan oleh pasien yang belum terkena infeksi, tetapi diduga mempunyai peluang untuk mendapatkan infeksi, atau bila terkena infeksi akan memiliki dampak buruk bagi pasien. Penggunaan antibiotik profilaksis diperlukan karena terbukti dapat mencegah atau mengurangi kejadian infeksi. Ketidaktepatan pemilihan antibiotik, indikasi, dosis, waktu pemberian, lama pemberian, serta rute pemberian adalah penyebab tidak tepat pengobatan infeksi dengan antibiotik. Tujuan penelitian ini adalah untuk mengevaluasi penggunaan antibiotik profilaksis cefazolin pada pasien operasi di Rumah Sakit Premier Bintaro periode Juli - Desember 2017. Penelitian ini bersifat non eksperimental dengan pengambilan data secara retrospektif dan dianalisa dengan deskriptif kuantitatif. Penelitian ini dilaksanakan di Rumah sakit Premier Bintaro dari bulan April - Mei. Sampel diambil dengan metode purposive sampling. Sampel adalah rekam medik pasien operasi yang menggunakan cefazolin sebagai antibiotik profilaksis, berjumlah 231 sampel. Instrument pengumpulan data menggunakan ceklist ketepatan penggunaan antibiotik profilaksis yang diisi oleh peneliti. Hasil penelitian ini menunjukkan presentasi tertinggi usia pasien adalah usia dewasa (1840) tahun sebanyak $45,9 \%$, tepat indikasi penggunaan $100 \%$, tepat dosis $99,1 \%$, tepat waktu pemberian $77,5 \%$, tepat lama pemberian 93,5\%, tepat rute pemberian $100 \%$. Kesimpulan dari penelitian ini adalah masih adanya ketidaktepatan dalam pemberian antibiotik profilaksis cefazolin pada pasien operasi dalam hal dosis, waktu pemberian, dan lama pemberian.
\end{abstract}

Kata kunci : antibiotik profilaksis, pasien operasi, rumah sakit

\begin{abstract}
Prophylactic antibiotics are antibiotic used by patients who have not been infected but are thought to have the chance to get an infection or if an infection will have an adverse effect on the patient. The use of prophylactic antibiotics is needed because it is proven to prevent or reduce the incidence of infection. Inaccurate selection of antibiotic, indication, dosage, time of administration, duration of administration, and route of administration causes inappropriate treatment infections with antibiotic. The objective of this study was to evaluate the use of prophylactic antibiotics cefazolin in surgical patients at the premier bintaro hospital in the period of july - December 2017. This study is non experimental with retrospective data collection and analyzed with quantitative descriptive. This research was carried out at premier bintaro hospital from april until may. Samples were taken by purposive sampling method. Samples are medical record of surgery patients who use cefazolin as prophylactic antibiotic, with 231 samples. Data collection instrument uses a checklist of accuracy of the use prophylactic antibiotic filled by researcher. The result showed the highest presentation of the age patients was adult age (18-40) year is 45,9\%, right indication of the use $100 \%$, right dosis 99,1\%, right time administration 77,5\%, right duration administration 93,5\%, and right route administration $100 \%$. The conclusion of this study is stil inaccuracies in the administration of prophylactic antibiotic cefazolin in surgical patients in term of dosage, time of administration, and duration of administration.
\end{abstract}

Keywords $\quad$ : prophylactic antibiotic, surgery patient, hospital 


\section{PENDAHULUAN}

Antibiotik profilaksis adalah antibiotik yang digunakan oleh pasien yang belum terkena infeksi, tetapi diduga mempunyai peluang untuk mendapatkan infeksi, atau bila terkena infeksi akan memiliki dampak buruk bagi pasien (Kemenkes, 2011)

Pada kasus operasi, penggunaan antibiotik profilaksis terbukti dapat mengurangi dan atau mencegah kejadian infeksi luka operasi. Dampak negatif yang paling bahaya dari penggunaan antibiotik secara tidak rasional adalah terjadinya bahaya resistensi antibiotik. Hal ini menyebabkan pengobatan tidak efektif, meningkatkan angka mortalitas pasien, dan peningkatan biaya rawat.

Pada penelitian terdahulu, di RSUD Dr. Soetomo dan RSUD Dr. Kariadi tahun 2008 menunjukkan 53\% pasien di rumah sakit mendapatkan resep antibiotik terapi, $15 \%$ mendapatkan antibiotik profilaksis, dan $32 \%$ untuk indikasi yang tidak diketahui, dan ditemukan beberapa kuman patogen yang resisten terhadap antibiotik. Dilaporkan insiden infeksi luka operasi di Korea $(4,6 \%)$, Brazil $(7,2 \%)$, China $(6,2 \%)$, (Guanche garcell,et al,2017).

Salah satu faktor penyebab meningkatnya infeksi luka operasi adalah pemberian antibiotik profilaksis yang tidak rasional, diantaranya salah pemilihan jenis, rute pemberian yang salah, waktu pemberian yang tidak benar, serta dosis yang inadekuat.

Hasil diskusi dengan Apoteker di Rumah Sakit Premier Bintaro menyatakan bahwa adanya permintaan dokter dalam penulisan resep antibiotik profilaksis pada kasus pasien operasi masih ditemukan ketidak tepatan berupa pemilihan jenis antibiotik terapi yang sama dengan antibiotik profilaksis, serta lama pemberian dari antibiotik tersebut.

Tujuan dari penelitian ini adalah untuk mengevaluasi penggunaan antibiotik profilaksis cefazolin pada pasien operasi di Rumah Sakit Premier Bintaro periode Juli - Desember 2017 berdasarkan demografi pasien, ketepatan indikasi, dosis, waktu pemberian, lama pemberian, dan rute pemberian.

\section{METODE}

Penelitian ini merupakan jenis penelitian non eksperimental dengan pengambilan data secara retrosepektif dari rekam medik pasien dan dianalisa secara deskriptif kuantitatif. Data yang digunakan dalam penelitian ini adalah data sekunder. yang diperoleh peneliti dari sumber yang sudah ada. Data 
sekunder dalam penelitian ini berupa data rekam medik pasien.

Populasi penelitian ini adalah seluruh data rekam medik pasien yang melakukan tindakan operasi di Rumah Sakit Premier Bintaro periode Juli Desember 2017 dihitung dari tindakan operasi yang tergolong operasi bersih dan bersih kontaminasi. Sampel diambil dengan metode purposive sampling. Sampel penelitian ini adalah yang memenuhi kriteria inklusi dan tidak memenuhi kriteria eklusi.

Instrumen yang digunakan dalam penelitian ini adalah checklist ketepatan penggunaan antibiotik profilaksis cefazolin pada pasien operasi di rumah sakit Premier Bintaro Periode Juli Desember 2017.

Analisa data dilakukan secara deskriptif kuantitatif dengan menyimpulkan data yang diperoleh dari rekam medik pasien berdasarkan parameter tepat pasien, tepat indikasi, tepat dosis, tepat waktu pemberian, tepat lama pemberian, dan rute pemberian.

Data yang dikumpulkan kemudian dilakukan tabulasi dan dianalisa dengan menggunakan rumus persentase

$$
\mathrm{P}=\frac{F}{n} \times 100 \%
$$

\section{Keterangan:}

$\mathrm{P}=$ persentase

$\mathrm{F}=$ frekuensi tiap kategori

$\mathrm{n}=$ jumlah sampel

\section{HASIL}

Tabel 1. Demografi Usia

\begin{tabular}{cccc}
\hline No & Usia & Jumlah Sampel (pasien) & Presentasi (\%) \\
\hline $\mathbf{1}$ & Balita (0-5 tahun) & 4 & $1,7 \%$ \\
\hline $\mathbf{2}$ & Anak (6-11 tahun) & 6 & $2,6 \%$ \\
\hline $\mathbf{3}$ & $\begin{array}{c}\text { Remaja (12-17 } \\
\text { tahun) }\end{array}$ & 17 & $7,4 \%$ \\
\hline $\mathbf{4}$ & $\begin{array}{c}\text { Dewasa (18-40 } \\
\text { tahun }\end{array}$ & 106 & $45,9 \%$ \\
\hline $\mathbf{5}$ & Tua (41-65 tahun & 98 & $42,4 \%$ \\
\hline & Jumlah & 231 & $100 \%$ \\
\hline
\end{tabular}

Sumber : Data Primer 
Berdasarkan tabel 1, dapat dilihat rentang usia pasien yang mendapatkan antibiotik cefazolin yaitu di usia balita sampai masa tua. Balita (0-5) sebanyak $1,7 \%$, anak (6-11) sebanyak $2,6 \%$, remaja (12-17) sebanyak 7,4 \%, dewasa (18-40) sebanyak 45,9\%, masa tua (41-65) sebanyak $42,4 \%$.

Tabel 1. Tepat Indikasi

\begin{tabular}{llcc}
\hline No & $\begin{array}{c}\text { Ketepatan } \\
\text { Indikasi }\end{array}$ & $\begin{array}{c}\text { Jumlah } \\
\text { sampel } \\
\text { (pasien) }\end{array}$ & $\begin{array}{c}\text { Presentasi } \\
(\mathbf{\%})\end{array}$ \\
\hline 1 & $\begin{array}{l}\text { Tepat } \\
\text { Indikasi }\end{array}$ & 231 & 100 \\
\hline 2 & $\begin{array}{l}\text { Tidak Tepat } \\
\text { Indikasi }\end{array}$ & 0 & 0 \\
\hline & Jumlah & 231 & 100 \\
\hline
\end{tabular}

Sumber : Data Primer

Berdasarkan tabel 2, indikasi penggunaan antibiotik profilaksis cefazolin untuk pasien operasi di Rumah Sakit Premier Bintaro periode Juli Desember 2017 adalah $100 \%$ tepat indikasi

Tabel 2. Tepat Dosis

\begin{tabular}{llcc}
\hline No & $\begin{array}{c}\text { Ketepatan } \\
\text { Dosis }\end{array}$ & $\begin{array}{c}\text { Jumlah } \\
\text { sampel } \\
\text { (pasien) }\end{array}$ & $\begin{array}{c}\text { Presentasi } \\
(\%)\end{array}$ \\
\hline 1 & Tepat Dosis & 229 & $99,1 \%$ \\
\hline 2 & $\begin{array}{l}\text { Tidak Tepat } \\
\text { Dosis }\end{array}$ & 2 & $0,9 \%$ \\
\hline & Jumlah & 231 & $100 \%$
\end{tabular}

Sumber : Data Primer

Berdasarkan tabel 3, ketepatan dosis penggunaan antibiotik profilaksis cefazolin pada pasien operasi di Rumah Sakit Premier Bintaro periode Juli Desember 2017 adalah 99,1\% tepat dosis, dan masih ada $0,9 \%$ tidak tepat dosis.

Tabel 3. Tepat Waktu Pemberian

\begin{tabular}{|llcc}
\hline No & $\begin{array}{c}\text { Ketepatan } \\
\text { Waktu } \\
\text { Pemberian }\end{array}$ & $\begin{array}{c}\text { Jumlah } \\
\text { sampel } \\
\text { (pasien) }\end{array}$ & $\begin{array}{c}\text { Presentasi } \\
(\mathbf{\%})\end{array}$ \\
\hline 1 & Tepat waktu & 179 & 77,5 \\
\hline 2 & $\begin{array}{l}\text { Tidak Tepat } \\
\text { waktu }\end{array}$ & 52 & 22,5 \\
\hline & Jumlah & 231 & 100 \\
\hline
\end{tabular}

Sumber : Data Data Primer

Berdasarkan tabel 4, diperoleh ketepatan waktu pemberian antibiotik profilaksis pada pasien operasi di Rumah Sakit Premier Bintaro periode Juli Desember adalah $77,5 \%$ tepat waktu pemberian, sementara masih ada $22,5 \%$ tidak tepat waktu pemberian antibiotik profilaksis.

Tabel 4 Tepat lama Pemberian

\begin{tabular}{llcc}
\hline No & $\begin{array}{c}\text { Ketepatan } \\
\text { Lama } \\
\text { Pemberian }\end{array}$ & $\begin{array}{c}\text { Jumlah } \\
\text { sampel } \\
\text { (pasien) }\end{array}$ & $\begin{array}{c}\text { Presentasi } \\
(\%)\end{array}$ \\
\hline $\mathbf{1}$ & $\begin{array}{l}\text { Tepat lama } \\
\text { pemberian }\end{array}$ & 216 & $93,5 \%$ \\
\hline $\mathbf{2}$ & $\begin{array}{l}\text { Tidak Tepat } \\
\text { lama }\end{array}$ & 15 & $6,5 \%$ \\
\hline
\end{tabular}


pemberian

Jumlah

231

$100 \%$

Sumber : Data Primer

Berdasarkan tabel 5, diperoleh lama pemberian antibiotik profilaksis cefazolin pada pasien operasi di Rumah Sakit Premier Bintaro periode Juli - Desember 2017 adalah 93,5\% tepat lama pemberian, sementara masih ada $6,5 \%$ tidak tepat lama pemberian antiobiotik profilaksis.

Tabel 5. Tepat Rute Pemberian

\begin{tabular}{llcc}
\hline No & $\begin{array}{c}\text { Ketepatan } \\
\text { Rute } \\
\text { Pemberian }\end{array}$ & $\begin{array}{c}\text { Jumlah } \\
\text { sampel } \\
\text { (pasien) }\end{array}$ & $\begin{array}{c}\text { Presentasi } \\
(\%)\end{array}$ \\
\hline 1 & $\begin{array}{l}\text { Tepat Rute } \\
\text { Pemberian }\end{array}$ & 231 & 100 \\
\hline 2 & $\begin{array}{l}\text { Tidak Tepat } \\
\text { Rute } \\
\text { Pemberian }\end{array}$ & 0 & 0 \\
\hline & Jumlah & 231 & 100
\end{tabular}

Sumber : Data Primer

Dari tabel 6, dapat disimpulkan semua tindakan operasi di Rumah Sakit Premier Bintaro periode Juli - Desember 2017 antibiotik profilaksis diberikan secara intravena, sehingga ketepatan pemberian antibiotik profilaksis adalah $100 \%$.

\section{DISKUSI}

Berdasarkan tabel 1.1 diketahui Persentase terbanyak pasien yang melakukan tindakan operasi ada di usia dewasa yaitu 45,9\% ( 106 pasien ) dan masa tua yaitu 42,4\% ( 98 pasien ). Hasil tersebut menunjukkan bahwa tindakan operasi pada usia dewasa dan masa tua lebih banyak dibanding dengan usia balita sampai usia remaja karena pada masa dewasa dan tua ada penurunan fungsi organ dalam tubuh serta berkurangnya metabolisme dalam tubuh yang normal. Hal ini bisa juga dilihat dari diagnosa tindakan operasi yang ada seperti operasi Caesar, operasi lutut, operasi panggul, operasi tulang yang banyak dilakukan pada usia dewasa dan tua.

Antibiotik profilaksis diberikan pada pasien yang akan melakukan tindakan operasi yang tergolong operasi bersih dan bersih kontaminasi. Berdasarkan tabel 1.2 indikasi penggunaan antibiotik profilaksis cefazolin yaitu $100 \%$ tepat indikasi.

Hal ini membuktikan bahwa kepatuhan dokter dalam peresepan antibiotik profilaksis sudah tepat, dokter sudah mengikuti pedoman penggunaan antiobiotik profilaksis yang sesuai, serta dokter mendukung program pengendalian resistensi antibiotik yang merupakan bagian dari antibiotik stewardship.

Dosis antibiotik profilaksis cefazolin diberikan 1-2 gram untuk 
dewasa dan untuk anak 25 - $50 \mathrm{mg} / \mathrm{KgBB}$ tergantung dengan tindakan operasi yang dilakukan. Berdasarkan tabel 1.3 masih ada $0,9 \%$ penggunaan antibiotik profilaksis tidak tepat dosis.

Pasien tersebut seharusnya mendapatkan dosis antibiotik 50 $\mathrm{mg} / \mathrm{KgBB}$ sesuai tindakan operasi, yaitu $450 \mathrm{mg}$ untuk pasien dengan berat badan $9 \mathrm{~kg}$, serta $500 \mathrm{mg}$ untuk pasien dengan berat badan $10 \mathrm{~kg}$, namun pasien tersebut hanya mendapatkan $200 \mathrm{mg}$ untuk yang berat badan $9 \mathrm{~kg}$ dan $300 \mathrm{mg}$ untuk yang berat badan $10 \mathrm{~kg}$.

Hasil penelitian pada evaluasi tepat waktu pemberian bertujuan untuk melihat kapan antibiotik profilaksis diberikan sebelum tindakan operasi, dimana antibiotik tersebut diberikan 30 60 menit sebelum insisi awal supaya pada saat insisi kadar obat mencapai puncak pada jaringan untuk menghambat pertumbuhan bakteri. Berdasarkan tabel 1.4 masih ditemukan ketidaktepatan waktu pemberian antibiotik profilaksis sebanyak 22,5\%. Ketidaktepatan waktu pemberian karena obat sudah diberikan namun terjadinya pengunduran jadwal operasi.

Hasil penelitian pada tepat lama pemberian antibiotik profilaksis untuk melihat berapa banyak antibiotik profilaksis tersebut masuk kedalam tubuh pasien, dimana antibiotik profilaksis hanya diberikan satu kali sebelum insisi, atau bila ada pengulangan maksimal $1 \mathrm{x}$ 24 jam. Bila operasi berlangsung lebih dari 4 jam dan pendarahan lebih dari 1500 $\mathrm{ml}$ dosis antibiotik profilaksis dapat diulang tiap 4 jam selama tindakan operasi. Berdasarkan tabel 1.5 masih didapatkan $6,5 \%$ tidak tepat lama pemberian antibiotik profilaksis. Ketidaktepatan itu berupa pemberian jenis antibiotik terapi di ruang keperawatan sama dengan antibiotik profilaksis.

\section{Antibotik profilaksis diberikan} secara intravena karena pemberian dengan rute ini mempunyai keuntungan yaitu obat cepat tersebar merata ke seluruh jaringan sehingga mencegah terjadinya infeksi luka operasi. Berdasarkan tabel 1.6 ketepatan rute pemberian antibiotik profilaksis adalah $100 \%$ tepat rute pemberian.

\section{SIMPULAN}

Dari hasil penelitian ini diperoleh data bahwa pasien yang menjalani operasi di Rumah Sakit Premier Bintaro periode Juli - Desember 2017 yang mendapatkan antibiotik profilaksis cefazolin terbanyak di rentang usia dewasa $(45,9 \%)$ dan tua $(42,4 \%)$, ketepatan indikasi penggunaan 
antibiotik profilaksis cefazolin $100 \%$ tepat indikasi, ketepatan dosis penggunaan antibiotik profilaksis cefazolin $99,1 \%$ tepat dosis, ketepatan waktu pemberian antibiotik profilaksis cefazolin $77,5 \%$ tepat waktu pemberian, ketepatan lama pemberian antibiotik profilaksis cefazolin $93,5 \%$ tepat lama pemberian, dan ketepatan rute pemberian antibiotik profilaksis cefazolin 100 $\%$ tepat rute pemberian.

\section{DAFTAR PUSTAKA}

American society of health-system pharmacist. 2013. Clinical practice guidelines for antimicrobial prophylaxis in surgery. Therapeutic guidelines. ASHP: h 582-587

Apriliana, W. 2017. Evaluasi rasionalitas penggunaan antibiotik profilaksis operasi apendisitis akut pasien dewasa dan geriatri di RS Bethesda Yogyakarta 2015. Yogyakarta: fakultas farmasi Universitas Gadjah Mada;

Avenia N, Sanguinetti A, Cirrochi R.et al. 2009. Antibiotic prophylaxis in surgery. Antibi Annal of surgical innovation and research

Kementerian kesehatan Republik Indonesia. 2011. Pedoman pelayanan kefarmasian untuk terapi antibiotik. Jakarta:

Kementerian kesehatan Republik Indonesia. 2011. Pedoman uтum penggunaan antibiotik. Jakarta:

Kementrian kesehatan Republik

Indonesia. $2015 . \quad$ Program pengendalian resistensi antimikroba di Rumah Sakit. Jakarta:

Komite Farmasi dan Terapi. 2016. Pedoman penggunaan antibiotik profilaksis. RSPB;

Komite PPRA. 2018. Program pengendalian resistensi antimikroba . RSPB;

Roger W, Clive E. 2014. Surgical antibiotic prophylaxis. Clinical Pharmacy and Therapeutics . International edition h. 539-543

Sugiyono. 2011. Metode penelitian kuantitatif kualitatif dan $R \& D$. Alfabeta 